\title{
Inhibition of the estrous cycles of rats by REM sleep deprivation
}

\author{
KRISTEN A. LINDSETH, ROBERT A. HICKS, and HENRY A. LEON \\ San Jose State University, San Jose, California 95192
}

\begin{abstract}
The effects of REM sleep deprivation were tested on the estrous cycles of groups of 90and 270-day-old Sprague-Dawley female rats in a design that controlled for stress. REM deprivation was found to have a disruptive effect on the estrous cycle that was independent of age and/or sexual experience.
\end{abstract}

In what may be a unique observation, Kawakami and Sawyer (1959) have provided evidence that suggests that REM sleep increased during estrous in rabbits. Their data invite the hypothesis that REM sleep plays a role in the functioning of the estrous cycle, and this study was designed to investigate that relationship in an animal with regular estrous cycles.

\section{METHOD}

Eighteen 90-day-old, sexually naive, Sprague-Dawley derived female rats (weight $=260-290 \mathrm{~g}$ ) and 18 270-day-old SpragueDawley derived female rats (weight $=370-440 \mathrm{~g}$; all retired breeders) were randomly assigned to one of three treatments: a 4-day period of REM deprivation (RD), a 4-day swim stress control (SSC), or a home cage control (HCC). Thus, each treatment group was composed of six animals of each age. REM deprivation was accomplished using a procedure described in detail by Hicks, Pettey, Okuda, and Thomsen (1979). The swim stress procedure was one developed and used by Stern (1971) as a control for the RD procedures used here.

Before the animals were assigned to their treatments, each was observed for 8 days (or two complete estrous cycles) to determine the stage of estrus. For all animals, treatment was begun immediately following the 8 -day pretreatment period. Thus the stage of estrus at the beginning of treatment varied microscopically by a person naive to the animal's treatment, to determine the stage of estrous. For all animals, treatment was begun immediately following the 8 -day pretreatment period. Thus the stage of estrous at the beginning of treatment varied among the animals. After the initial 4-day treatment period, each animal was given a 4-day (home cage) recovery period, and then a second 4-day treatment period. As a consequence, each animal had the opportunity for a maximum of three complete (4-day) estrous cycles from the introduction of treatment to the termination of the study.

\section{RESULTS AND DISCUSSION}

The mean number of complete estrous cycles and the standard errors of the mean counted during the 12-day period of the study for each age by treatment group are listed in Table 1.

The data summarized in Table 1 were tested using a 2 (age) by 3 (treatments) factor analysis of variance,

H. A. Leon is affiliated with the Ames Research Center, Moffett Field, California 94035. Address all correspondence to Robert A. Hicks, Department of Psychology, San Jose State University, San Jose, California 95192.
Table 1

Mean Number of Complete Estrous Cycles and the Standard Deviation for Each Age by Treatment Group

\begin{tabular}{|c|c|c|c|c|c|c|}
\hline \multirow{2}{*}{$\begin{array}{c}\text { Age (in } \\
\text { Days) }\end{array}$} & \multicolumn{2}{|c|}{ Treatment RD } & \multicolumn{2}{|c|}{ Treatment SS } & \multicolumn{2}{|c|}{ Treatment $\mathrm{HCC}$} \\
\hline & Mean & SD & Mean & SD & Mean & SD \\
\hline $\begin{array}{r}90 \\
270\end{array}$ & $\begin{array}{r}.7 \\
1.2\end{array}$ & $\begin{array}{r}.8 \\
1.0\end{array}$ & $\begin{array}{l}2.3 \\
2.2\end{array}$ & $\begin{array}{l}1.2 \\
1.2\end{array}$ & $\begin{array}{l}3.0 \\
2.5\end{array}$ & $\begin{array}{l}.0 \\
.6\end{array}$ \\
\hline
\end{tabular}

with these results: The effect of treatments was significant $[F(2,30)=23.43, p<.001]$ and the effect of age and the Age by Treatment interaction were not significant $[\mathrm{F}(1,30)=.07$, and $\mathrm{F}(2,30)=1.70$, respectively $]$.

These data suggest that RD disrupts the estrous cycle of rats in a manner that is independent of age and/or sexual experience. Further, it seems unlikely that the disruptive effects of RD can be explained in terms of stress induced by the $\mathrm{RD}$ procedure.

The statistical data cited above do not fully convey the extent or the nature of the effects that RD had upon the estrous cycles of these animals. To explain, 11 of the $12 \mathrm{RD}$ animals (i.e., the 90-day and 270-day groups combined) had disrupted estrous cycles. In all of these animals, cycles were interrupted by extended periods of diestrus. In 8 of the $12 \mathrm{RD}$ animals, the estrous cycle was abolished during the first 4-day period of RD. Four of these animals displayed diestrous smears on 11 of 12 days of treatment (i.e., the two RD periods and the intervening 4-day recovery period).

Thus it is evident that RD had a disruptive effect on the estrous cycles of rats. While we feel that these data require further elaboration, they certainly suggest the need to routinely consider sex as a variable in $R D$ behavioral research in which rats are used as subjects.

\section{REFERENCES}

Hicks, R. A., Pettey, B., Okuda, A., \& Thomsen, D. The effects of REM sleep deprivation and age on locomotor activity in rats. Psychological Record, 1979, 29, 355-360.

KaWAKami, M., \& SawYer, C. H. Induction of behavioral and electroencephalographic changes in the rabbit by hormone administration or brain stimulation. Endocrinology, 1959, 65, 631-653.

Ste RN, W. C. Acquisition impairments following rapid eye movement sleep deprivation in rats. Physiology \& Behavior, 1971, 7, 345-353.

(Received for publication October 1, 1980.) 